\title{
A Rule-ordering Theory of Blocking in Nonderived Environments
}

\author{
Ezer Rasin \\ Massachusetts Institute of Techonology
}

\section{Introduction}

In Nonderived Environment Blocking (NDEB), a phonological process applies across morpheme boundaries or morpheme-internally when fed by another phonological process but is otherwise blocked from applying. A well-known example is Finnish assibilation (e.g., Kiparsky, 1993), which turns the stop [t] into the strident $[\mathrm{s}]$ before the high vowel [i]. The process applies before the past suffix -i (1-a); morphemeinternally, it applies only when the high vowel is the result of final-vowel raising (which raises [e] to [i] word-finally), as in (1-b); otherwise, assibilation does not apply within morphemes (1-c). The underlying sequence / $\mathrm{ti}$ / (prior to the application of assibilation) is often referred to as a derived environment in (1-a) and (1-b) and as a nonderived environment in (1-c).

a. Assibilation applies across a morpheme boundary:

halut-a 'want-INFINITIVE' vs. halus-i (/halut-i/) 'want-PAST'

b. Assibilation applies morpheme-internally when fed by final-vowel raising $(\mathrm{e} \rightarrow \mathrm{i} / \ldots$ _

vete-nä 'water-ESSIVE.SG.' vs. vesi (/vete/) 'water-NOM.SG.'

c. Otherwise, assibilation is blocked morpheme-internally:

(i) tila 'room-NOM.SG.'

(ii) äiti 'mother-NOM.SG.'

NDEB is an instance of under-application opacity that poses a challenge to both rule-based phonology and Optimality Theory (OT; Prince \& Smolensky, 1993): In rule-based phonology, a rule of assibilation that turns the stop [t] into the strident [s] before the high vowel [i] would incorrectly apply to nonderived /ti/ sequences if no conditions on its application are posited; similarly, in OT, the markedness constraint *ti would equally penalize derived and nonderived surface sequences of [ti]. And if *ti is allowed to be repaired by assibilation in derived environments (by appropriately ranking it over faithfulness constraints like IDENT[cont]), assibilation would incorrectly apply in nonderived environments as well. More generally, if $P$ is a process that is blocked in nonderived environments, the challenge in both frameworks is to partition the set of environments of application of $P$ into two subsets - corresponding to derived and nonderived environments - and block the application of the process precisely in nonderived environments.

Most previous literature on NDEB has tackled the challenge by introducing special mechanisms to distinguish derived from nonderived environments. Some representative examples are the Strict Cycle Condition (Mascaró, 1976), identity rules on lexical items combined with the Elsewhere Condition in Lexical Phonology and Morphology (Kiparsky, 1982), a distinction between "new" and "old" structure in Comparative Markedness (McCarthy, 2003), and morpheme coloring in Colored Containment (van Oostendorp, 2007).

My goal in this paper is to show that NDEB can be reduced to rule ordering. I will do so by presenting a rule-ordering theory of NDEB in which phonological rules are allowed to apply at the domain of the morpheme and affect individual morphemes before they are combined with other morphemes in morphologically-complex forms. Such rules were proposed in Halle (1959) and are familiar from the SPE (Chomsky \& Halle, 1968) and the later rule-based literature, where they were implemented as lexical redundancy rules or as morpheme structure constraints. Following Halle (1959), I will refer to such rules as

\footnotetext{
* I thank Adam Albright, Arto Antilla, Eric Baković, Edward Flemming, Morris Halle, Roni Katzir, Michael Kenstowicz, David Pesetsky, Donca Steriade, Sam Zukoff, and the participants in the MIT Workshop of Fall 2014.
} 
"Morpheme Structure Rules", and I will offer an implementation that unifies them with ordinary phonological rules in terms of format and mode of application. Morpheme structure rules will play a central role in the theory of NDEB presented in section 2: every rule $P$ that is blocked in nonderived environments will be ordered after a morpheme structure rule $R$ that removes $P$ 's environments of application. Since morpheme structure rules apply to URs of individual morphemes (which, as we will see, correspond to nonderived environments), $R$ will prevent $P$ from applying precisely in nonderived environments.

Section 2 presents the architecture (2.1) and a rule-ordering analysis of Finnish assibilation as a test case (2.2). In section 3 I compare the rule-ordering theory to the closely-related underspecification theory of NDEB proposed in Kiparsky (1993). I show that the rule-ordering theory, through its use of morpheme structure rules, is able to address the argument made in Burzio (2000) against Kiparsky's theory. In section 4 I show that the assumption of underspecification made in section 2 is not a necessary assumption for the rule-ordering theory.

\section{Proposal}

2.1 Architecture This subsection describes the phonological architecture that will be used in 2.2 for an account of NDEB. The architecture is schematized in Figure 1. A central component of the architecture is the mapping from URs to surface forms, which is implemented here using ordered phonological rules as in the SPE. I assume that a phonological grammar includes an alphabet, an inventory of feature bundles $\Sigma$, the elements of which can be concatenated. For example, if $k, a, t \in \Sigma$, then $\{k a t\}$ and $\{t a k t a\}$ are possible concatenations, among many others. I assume that individual languages can restrict $\Sigma$ to a proper subset, call it $\Sigma_{L}$. For a segment $\sigma \in \Sigma$, we can write $\sigma \notin \Sigma_{L}$, meaning that $\sigma$ cannot be used for concatenation in that language. For example, if English rules out /x/ from its alphabet and we write $x \notin \Sigma_{L}$, then $/ \mathrm{bax} /$ is not a possible concatenation in English. Negative statement such as $x \notin \Sigma_{L}$ are used for convenience and should not be taken to be grammatical constraints per se. What I mean by writing $x \notin \Sigma_{L}$ is that $\Sigma_{L}$, which could be positively stated in the grammar as a set of segments, does not include x. I will refer to representations created by concatenating elements from $\Sigma_{L}$ as initial representations, and I will mark them using curly brackets, e.g., $\{$ anta\}. Morpheme structure rules map initial representations to URs. For example, if $\{$ anta $\}$ is a an initial representation and post-nasal voicing $\left(\mathrm{t} \rightarrow \mathrm{d} / \mathrm{n}_{-}\right)$is the only morpheme structure rule in the grammar, the result of applying post-nasal voicing to $\{$ anta $\}$ is the UR /anda/. In this framework, then, URs are created in two steps: first, elements from $\Sigma_{L}$ are concatenated to form an initial representation. Then, morpheme structure rules apply and map this representation to a UR. Later on, phonological rules map URs to surface representations (SRs).

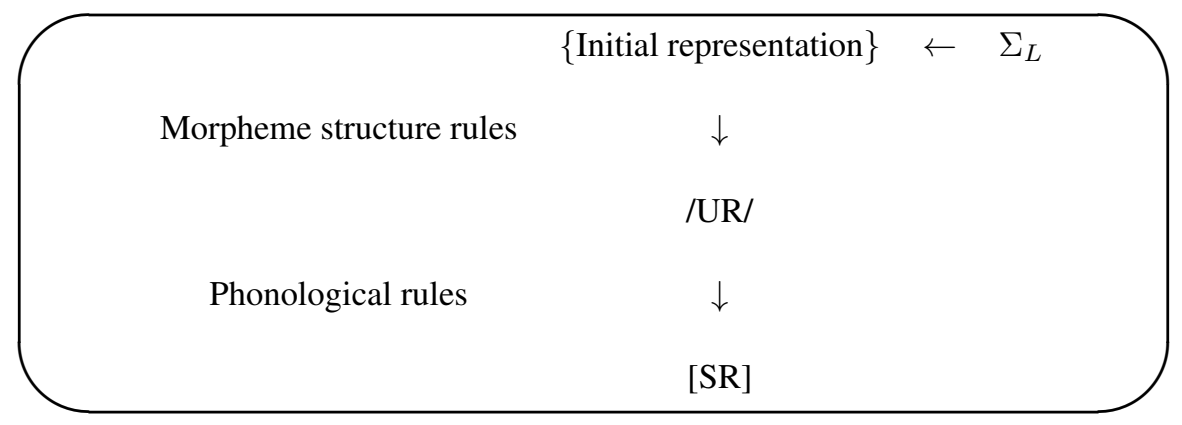

Figure 1: The architecture

In addition, I assume that lexical representations may be underspecified: segments in $\Sigma$ (and in $\Sigma_{L}$ ) may be underspecified for some of their features. ${ }^{1}$ For example, a variant of the voiceless alveolar stop [t] in which the feature [continuant] is not specified may be in $\Sigma$. We can refer to this segment as [T] and write $\mathrm{T} \in \Sigma$. Underspecified features are specified either by morpheme structure rules or by phonological rules. Finally, both morpheme structure rules and phonological rules may be feature filling. This means that they can target segments underspecified for some feature $F$ and fill in the relevant value but, crucially, without

1 Section 4 presents a variant of the rule-ordering theory that does not use underspecification. 
affecting segments that are already specified for $F$. For example, Finnish assibilation could be described as a rule that turns underspecified [T] into fully-specified [s] before an [i]. The rule and its effect on two URs are given in (2), demonstrating the property of feature filling,

(2) Assibilation: $\mathrm{T} \rightarrow \mathrm{s} /$ i $_{\text {i feature-filling) }}$
a. $\quad / \mathrm{Ti} / \stackrel{\text { assibilation }}{\longrightarrow}[\mathrm{si}]$
b. $\quad / \mathrm{ti} / \stackrel{\text { assibilation }}{\longrightarrow}[\mathrm{ti}]$

2.2 Analysis In this subsection I provide an analysis of NDEB using the architecture described in 2.1 and Finnish assibilation as a test case. The basic pattern of Finnish assibilation was presented above in (1-a)-(1-c), and is repeated here as (3-a)-(3-c). Following the convention in the literature, I use the term morphologicallyderived environment to refer to an environment created through affixation, as in (3-a), and phonologicallyderived environment to refer to an environment created through the application of a phonological process, as in (3-b).
a. Assibilation applies across a morpheme boundary: halut-a 'want-INFINITIVE' vs. halus-i 'want-PAST'
b. Assibilation applies morpheme-internally when fed by final-vowel raising $(\mathrm{e} \rightarrow \mathrm{i} / \ldots$ \#): vete-nä 'water-ESSIVE.SG.' $\quad$ vs. vesi 'water-NOM.SG.'
c. Otherwise, assibilation is blocked morpheme-internally:
(i) tila 'room-NOM.SG.'
(ii) äiti 'mother-NOM.SG.'

The first ingredient in the analysis is the rule of assibilation (4), which, following Kiparsky (1993), I take to be a feature-filling rule that specifies the voiceless alveolar $[\mathrm{T}]$ as [+continuant]. ${ }^{2}$ The second ingredient is a rule that I refer to as anti-assibilation (5). The rule of anti-assibilation is similar to assibilation: it is a feature-filling rule that applies in the same environment (/Ti/) and fills in a value for the feature [continuant]. The only difference is that anti-assibilation specifies that value as [-continuant] rather than [+continuant]. That is, anti-assibilation specifies $[\mathrm{T}]$ as [t].

$$
\begin{array}{ll}
\text { (4) Assibilation } \\
\\
\mathrm{T} \rightarrow \mathrm{s} / \mathrm{i}_{\text {(5) }} \text { (feature-filling) } \\
\text { Anti-assibilation } \\
\mathrm{T} \rightarrow \mathrm{t} / \mathrm{i}_{\text {i }} \text { (feature-filling) }
\end{array}
$$

To see how assibilation and anti-assibilation interact, consider the UR /Ti/ and a hypothetical grammar in which anti-assibilation is ordered before assibilation. The derivation is provided in (6). First, anti-assibilation applies and specifies [T] as [t]. Then, assibilation does not apply since its structural description is not met: the rule is feature filling, but [t] is not underspecified for continuance. The result is the surface form [ti]. In short, anti-assibilation bleeds assibilation by removing its environment of application.

(6) Interaction between assibilation and anti-assibilation (hypothetical grammar)

\begin{tabular}{l|c}
$\mathrm{UR}$ & $/ \mathrm{Ti} /$ \\
\hline $\mathrm{T} \rightarrow \mathrm{t} / \mathrm{i}^{\mathrm{i}}$ & $\mathrm{ti}$ \\
$\mathrm{T} \rightarrow \mathrm{s} / \mathrm{i}^{\mathrm{i}}$ & - \\
\hline $\mathrm{SR}$ & {$[\mathrm{ti}]$}
\end{tabular}

My proposal is that in the actual grammar of Finnish, anti-assibilation is a morpheme structure rule that applies in the morpheme structure component, whereas assibilation is a phonological rule that is part of the mapping from URs to surface forms. Fully-specified [t] is removed from the Finnish alphabet.

(7) Morpheme structure component:

$$
\text { a. } \quad \mathrm{t} \notin \Sigma_{L}
$$

2 For presentational ease, I ignore the feature [strident], which could be filled in by the assibilation rule itself or by a separate rule. 
b. $\quad \mathrm{T} \rightarrow \mathrm{t} / \mathrm{i}$

The consequence for the form of URs in Finnish is that /t/ and /T/ are in complementary distribution in the lexicon: /t/ occurs only before /i/ (following the application of anti-assibilation) and /T/ occurs elsewhere. Here are some examples. (8-a) shows the derivation of the UR /tila/. Since $t \notin \Sigma_{L}$, any instance of /t/ in URs must be derived from /T/. The initial representation is therefore $\{$ Tila\}, which anti-assibilation maps to /tila/. (8-b) indicates that /lata/ is not a possible UR in Finnish: since $\mathrm{t} \notin \Sigma_{L}$ and the environment for anti-assibilation is not met before /a/, /t/ cannot occur in a a pre-/a/ position.
a. $\quad\{$ Tila $\} \rightarrow /$ tila/
b. $*$ /lata/
c. /laTa/, /haluT/

In (8-c), anti-assibilation does not apply, and /T/ remains underspecified. The value for [continuant] will be filled by the mapping from URs to surface forms: the rule of assibilation turns /T/ into [s] before [i]; otherwise - that is, whenever assibilation does not apply $-/ \mathrm{T} /$ is specified as $/ \mathrm{t} /$ through the default rule $\mathrm{T} \rightarrow \mathrm{t}$.

(9) Phonological rules:

a. $\quad \mathrm{T} \rightarrow \mathrm{s} / \mathrm{i}$

b. $\quad \mathrm{T} \rightarrow \mathrm{t}$

(11) demonstrates the application of phonological rules in the derivation of the alternants in (10), assuming the UR /haluT/ for the stem.

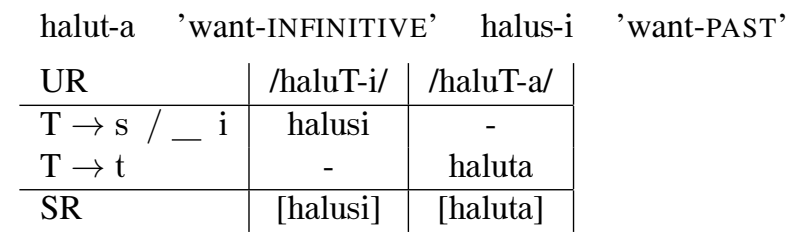

This is the grammar of Finnish we have so far:

a. Morpheme structure component:

(i) $\quad \mathrm{t} \notin \Sigma_{L}$

(ii) $\mathrm{T} \rightarrow \mathrm{t} / \mathrm{i}_{\mathrm{i}}$

b. Phonological rules:

(i) $\mathrm{T} \rightarrow \mathrm{s} / \mathrm{i}^{\mathrm{i}}$

(ii) $\mathrm{T} \rightarrow \mathrm{t}$

I will now show why this grammar applies assibilation in morphologically-derived environments but not in nonderived environments. Consider the derivation of [tilas-i], which alternates with [tilat-a] and includes two potential environments for the application of assibilation: the first is morpheme-internal, and the second spans the morpheme boundary. Assibilation only applies in the latter.

$$
\text { tilat-a 'order-INFINITIVE' vs. tilas-i 'order-PAST' }
$$

First, morpheme structure rules apply to each morpheme individually (14). Since $t \notin \Sigma_{L}$, the UR of the stem must be $\{$ TilaT $\}$. Anti-assibilation applies to the first instance of [T], but not to the second: at this stage of the derivation, the second [T] is stem-final and the environment for anti-assibilation is not met. The result is the UR /tilaT/, where only the second [T] remains underspecified for continuance. In the mapping from URs to surface forms, assibilation successfully applies to the sequence /T-i/ which was created through affixation. It does not apply to the stem-initial/ti/, which at this point is already fully specified. The final surface form is therefore [tilasi].

Derivation of [tilas-i] (infinitive: [tilat-a])

a. Morpheme structure rules apply to each morpheme individually:

(i) $\quad\{$ TilaT $\} \rightarrow /$ tilaT/ 
(ii) $\quad$ i $\} \rightarrow$ /i/

b. Phonological rules apply:

\begin{tabular}{l|c}
$\mathrm{UR}$ & $/$ tilaT-i/ \\
\hline $\mathrm{T} \rightarrow \mathrm{s} / \mathrm{i}^{\mathrm{i}}$ & tilas-i \\
$\mathrm{T} \rightarrow \mathrm{t}$ & - \\
\hline $\mathrm{SR}$ & [tilasi]
\end{tabular}

The next step is to show why assibilation applies in phonologically-derived environments. Recall that finalvowel raising (15) raises a word-final [e] to [i] (16-a). Assibilation may apply morpheme-internally when fed by final-vowel raising (16-b).

$$
\begin{array}{lrlll}
\mathrm{e} \rightarrow \mathrm{i} / \ldots \# & & & \\
\text { a. joke-nä } & \text { 'river-ESSIVE.SG.' } & \text { vs. joki 'river-NOM.SG.' } \\
\text { b. } & \text { vete-nä } & \text { 'water-ESSIVE.SG.' } & \text { vs. } & \text { vesi 'water-NOM.SG.' }
\end{array}
$$

Here, nothing further has to be said. Final-vowel raising is ordered before assibilation (17). In words like [vesi], alternating /T/ precedes /e/ in the UR, so anti-assibilation does not get to apply; /T/ remains underspecified, which means that assibilation will get to apply after affixation. The full derivation is provided in (18).

a. Morpheme structure component:

(i) $\mathrm{t} \notin \Sigma_{L}$

(ii) $\mathrm{T} \rightarrow \mathrm{t} / \mathrm{i}_{\mathrm{i}}$

b. Phonological rules:

(i) $\mathrm{e} \rightarrow \mathrm{i} / \ldots \#$

(ii) $\mathrm{T} \rightarrow \mathrm{s} /{ }_{-} \mathrm{i}$

(iii) $\mathrm{T} \rightarrow \mathrm{t}$

(18) Derivation of [vesi]

a. Morpheme structure rules apply (vacuously): $\{$ veTe $\rightarrow \quad /$ veTe/

b. Phonological rules apply:

\begin{tabular}{l|c}
$\mathrm{UR}$ & /veTe\#/ \\
\hline $\mathrm{e} \rightarrow \mathrm{i} /$ \# & veTi\# \\
$\mathrm{T} \rightarrow \mathrm{s} /$ i & vesi\# \\
$\mathrm{T} \rightarrow \mathrm{t}$ & - \\
\hline $\mathrm{SR}$ & [vesi]
\end{tabular}

This analysis captures the intuition that a process $P$ that is blocked in nonderived environments applies unless its environment of application is present in some UR. If the environment for $P$ is present underlyingly, the morpheme structure rule anti- $P$ applies and destroys the environment for $P$ through feature filling. On this view, NDEB is just like any other instance of opaque interaction between rules. NDEB is special because the interaction is between a morpheme structure rule that applies at the domain of the morpheme and an ordinary phonological rule.

\section{Comparison with Kiparsky (1993)}

The rule-ordering theory relied on the distinction between underspecification and full specification to block $P$ in nonderived environments: $P$ applied to underspecified segments but could not apply to fullyspecified segments. This distinction is central to Kiparsky's (1993) proposal: the mapping from URs to SRs is the same as in the rule-ordering account, but the morpheme structure component is absent. To see how Finnish assibilation would work in Kiparsky's theory, a fragment of the grammar and a sample derivation are provided in (19)-(20).

Finnish assibilation grammar under Kiparsky's proposal
a. $\quad \mathrm{T} \rightarrow \mathrm{s} / \mathrm{i}^{\mathrm{i}}$ 
b. $\quad \mathrm{T} \rightarrow \mathrm{t}$

\begin{tabular}{l|c}
\multicolumn{2}{l}{ Derivation of [tilasi] } \\
$\mathrm{UR}$ & /tilaT-i/ \\
\hline $\mathrm{T} \rightarrow \mathrm{s} /{ }^{\mathrm{i}}$ & tilas-i \\
$\mathrm{T} \rightarrow \mathrm{t}$ & - \\
\hline $\mathrm{SR}$ & [tilasi]
\end{tabular}

For Kiparsky, assibilation does not apply to the first [t] in [tilasi] since this instance of $[\mathrm{t}]$ is fully specified in the UR, but it applies to the underspecified [T] since alternating features are missing from the lexicon. As noted by Burzio (2000), this proposal leaves the underlying distribution of underspecified [T] and fullyspecified [t] as an accident of the Finnish lexicon: nothing prevents fully-specified [t] from occurring stemfinally and incorrectly blocking assibilation before a suffix-initial [i]. The grammar thus generates unattested ungrammatical forms such as *[rati] in which assibilation has not applied:

\begin{tabular}{l|c}
$\mathrm{UR}$ & $/ \mathrm{rat}-\mathrm{i} /$ \\
\hline $\mathrm{T} \rightarrow \mathrm{s} /-\mathrm{i}$ & - \\
$\mathrm{T} \rightarrow \mathrm{t}$ & - \\
\hline $\mathrm{SR}$ & $*$ [rati]
\end{tabular}

The rule-ordering theory rules out /rat/ as a UR since fully-specified [t] can only precede [i] in the lexicon. This restriction is enforced by the morpheme structure component, which prevents the grammar from incorrectly generating words such as *[rati].

\section{Underspecification vs. exception features}

The proposal sketched in section 2 makes use of underspecification to distinguish between alternating and non-alternating features: feature-filling rules apply to underspecified but not to specified features. There is no consensus in the literature regarding the availability of underspecification in phonology (see Steriade, 1995 for discussion). Many current theories of phonology reject it, and it will be useful to understand whether the present theory crucially relies on underspecification. My goal in this section is to show that the argument that NDEB can be reduced to rule ordering is independent of the availability of underspecification. I will do so by presenting a variant of the proposal which does not use underspecification but keeps all other ingredients of the proposal fixed. In particular, the distinction between unspecified and specified features can be replaced with a distinction between plain specified features and specified features alongside an exception diacritic that prevents the feature from being changed by a particular rule. On this variant, every rule is feature-changing and morpheme structure rules are responsible not for filling features in the lexicon but rather for introducing exception diacritics.

The representational differences between the two variants are summarized in table (22). The feature [-assibilation] in $\mathrm{t}_{\text {[-assibilation] }}$ indicates that the segment [t] is immune to the rule of assibilation. A fragment of Finnish under the exception-based variant is given in (23). Here, assibilation is a feature-changing rule that changes every instance of [t] to [s], unless it is marked with the exception feature [-assibilation]. For reasons discussed in the previous section, the distribution of exception features may not remain an accident of the Finnish lexicon: an instance of [t] must be marked with [-assibilation] precisely when it precedes an [i]. This distribution is enforced by the morpheme structure component. The end result is that assibilation applies unless its environment of application is present in the lexicon, as needed.

\begin{tabular}{l||cc} 
Variant & Alternating & Non-alternating \\
\hline \hline Underspecification & $\mathrm{T}$ & $\mathrm{t}$ \\
\hline Exceptions & $\mathrm{t}$ & $\mathrm{t}_{\text {[-assibilation] }}$ \\
\hline
\end{tabular}

a. Morpheme structure component:

(i) No exception features in $\Sigma_{L}$

(ii) $\mathrm{t} \rightarrow[$-assibilation $] / \ldots$ i

b. Phonological rules:

$\mathrm{t} \rightarrow \mathrm{s} / \mathrm{i}_{\mathrm{i}}$ 
At present, I am not aware of any evidence for choosing one variant over the other. Processes like epenthesis and deletion are not easily characterized using underspecification and may require some additional technical maneuvers from the underspecification variant. The underspecification variant may also be subject to Stanley's (1967) early conceptual objections to underspecified representations. The exception-based variant uses ad-hoc rule-specific features and is less general than the underspecification variant: underspecification of a feature like [cont] may have consequences for other rules that make reference to [cont] other than assibilation, and it remains to be seen whether this prediction is borne out. In any case, as both variants are currently equally successful empirically, I conclude that the success of the rule-ordering theory is independent of whether underspecification is available.

\section{References}

Burzio, Luigi (2000). Cycles, non-derived-environment-blocking, and correspondence. Dekkers, Joost, Frank van der Leeuw \& Jeroen van de Weijer (eds.), Optimality Theory: Phonology, Syntax, and Acquisition, Cambridge: Cambridge University Press.

Chomsky, Noam \& Morris Halle (1968). The Sound Pattern of English. Harper and Row Publishers, New York.

Halle, Morris (1959). The sound pattern of Russian. Walter de Gruyter.

Kiparsky, Paul (1982). Lexical phonology and morphology. Linguistics in the Morning Calm, Linguistics Society of Korea, Hanshin Publishing Company, Seoul, Korea.

Kiparsky, Paul (1993). Blocking in nonderived environments. Kaisse, Ellen M. \& Sharon Hargus (eds.), Phonetics and Phonology 4: Studies in Lexical Phonology, San Diego: Academic Press, 277-313.

Mascaró, Joan (1976). Catalan Phonology and the Phonological Cycle. Ph.D. thesis, MIT.

McCarthy, John (2003). Comparative markedness. Theoretical Linguistics 29, 1-51.

van Oostendorp, M. (2007). Derived environment effects and consistency of exponence. Blaho, Sylvia, Patrik Bye \& Martin Kraemer (eds.), Freedom of Analysis, Berlin: Mouton de Gruyter.

Prince, Alan \& Paul Smolensky (1993). Optimality theory: Constraint interaction in generative grammar. Tech. rep., Rutgers University, Center for Cognitive Science.

Stanley, Richard (1967). Redundancy rules in phonology. Language 43:2, 393-436.

Steriade, Donca (1995). Underspecification and markedness. Goldsmith, John (ed.), The Handbook of Phonological Theory, Blackwell, Oxford, 114-174. 